\title{
The Effects of Technology Innovativeness and System Exposure on Student Acceptance of E-textbooks
}

\author{
Madison N. Ngafeeson \\ College of Business, \\ Northern Michigan University, \\ Marquette, MI 49855
}

mngafees@nmu.edu

\author{
Jun Sun \\ Department of Information \\ Systems, University of Texas - \\ Rio Grande Valley, \\ Edinburg, TX 78539
}

\begin{abstract}
The efforts of educators in the last three decades have, among other things, focused on the use of information technology (IT) in education. It has become commonplace to view information systems both as an effective carrier of course content as well as a cost-effective tool to improve student learning outcomes. One of such technologies is the e-book. Decision-makers in the education field need make sense of this technological transformation. However, despite the growing popularity of e-books in higher education, its adoption by students is yet to be crystalized. This study exploits the technology acceptance model (TAM) framework to examine student acceptance of e-textbooks as "internally" impacted by technology innovativeness and "externally" influenced by system exposure. The results showed that students' technology innovativeness is associated with student acceptance of e-textbooks and that system exposure was a strong moderator of the TAM relationships. The findings suggest that students' openness to new technology, in general, is likely to positively affect the adoption of a specific new instructional technology. Additionally, system exposure was found to be a significant moderator of the TAM relationships. It is concluded that students' technology innovativeness and system exposure must therefore be factored into instructional technology usage decision-making models.
\end{abstract}

Keywords: technology acceptance model, instructional technology, e-book, IT education, technology innovativeness, technology exposure, e-book adoption, e-textbook acceptance.

\section{Introduction}

Material published as part of this publication, either on-line or in print, is copyrighted by the Informing Science Institute. Permission to make digital or paper copy of part or all of these works for personal or classroom use is granted without fee provided that the copies are not made or distributed for profit or commercial advantage AND that copies 1) bear this notice in full and 2) give the full citation on the first page. It is permissible to abstract these works so long as credit is given. To copy in all other cases or to republish or to post on a server or to redistribute to lists requires specific permission and payment of a fee. Contact Publisher@InformingScience.org to request redistribution permission.
In 2011 it was projected that digital textbooks sales in the United States will increase by $25 \%$ over a five-year period. The same report predicted that digital textbooks will be the most dominant form of textbooks in higher education in the following seven years, and can expected to boost revenues in excess of $\$ 1.5$ billion within the five years following (Reynolds, 2011) The study concludes that this growth will create op- 
portunities for new digital product models and new content publishers and potentially raise the formal adoption of open educational resources. The transmission, delivery, and use of electronic texts has become a common place element in library collections over the years (Hernon, Hopper, Leach, Saunders, \& Zhang, 2007).

E-books have been narrowly defined as being digital equivalents of the printed texts. In this regard, e-textbooks have been looked upon as possessing characteristics similar to the printed text in that they allow for students to underline important portions, write notes, or lookup unfamiliar words (Maynard \& Cheyne, 2005). On the higher end, current e-textbooks have a more complex functionality: from more complex user interfaces to functions that permit students to interact with instructor and peers. They also possess other functionalities for student assessments as well as enriched video interactions. E-book technology covers a broad spectrum of component technologies that may vary in their nature and extent, but the term e-book is generally used to encompass the "hardware, software and content" that it carries (Wilson \& Landoni, 2001, p. 2).

In this study we examine e-textbooks as used within an educational context for the purpose of instruction and learning. Hence, an e-textbook is defined as a piece of electronic text, regardless of size or digital object used, made available digitally for any device that uses a screen for the purpose of instruction and learning.

Libraries across the world continue to amass large volumes of online book resources especially in the academia. Many studies have reported a general positive attitude towards e-textbook usage. Nicholas, Rowlands, and Jamali (2010) report a study involving over 5000 students and staff on an e-book platform sustaining 127 universities in the United Kingdom. They conclude that etextbooks are increasingly popular and widely used. However, their findings show that users mainly use e-textbooks for obtaining snippets of information and for fact-finding, chiefly so because of the ease of access and convenience. Additional reports also indicate that doctoral students are more strongly associated to the use of e-textbooks than are undergraduate students (Lamothe, 2013). Evidence from the nine-year study showed that the size of an e-book collection as well as the content of an e-book collection was more important in determining patron usage. Other recent studies have engaged in understanding a discipline-based use of e-textbooks by students. Brunet, Bates, Gallo, and Strother (2011) examine acceptance among incoming dental students while Zhang and Beckman (2011) investigate its usage among chemists, biochemists, and biologists. Each one of these recent studies seems to agree on the fact that e-textbooks are continually gaining ground within higher educational settings. There also seems to be a recurrent theme of how to improve the e-textbook experience, its adoption, and its usage among students. For example, Brunet et al. (2011) found that only fewer students preferred e-textbooks compared to over half of the students in their study who were rather undecided about their preference of etextbooks over print textbooks. In a survey of graduate students, researchers, and faculty who use e-books, Zhang and Beckman (2011) report that e-book usage was gaining acceptance comparable to electronic journals, but with a caveat that skills and training was needed for greater adoption and acceptance.

Given the enormous resources that are being pumped into acquiring e-books for academic use, it would make sense to question the actual usage of these systems (Ismail \& Zainab, 2005; Nicholas et al., 2010). Evidence is needed to justify expenditures by academic institutions to this end (Hernon et al., 2007. Additionally, though college students are typically both the target and current greatest users of this e-textbooks (Hernon et al., 2007), research shows that adoption is still an unsettled issue (Sun, Flores, \& Tanguma, 2012). Many researchers have suggested measures to boost adoption. Instructor engagement in developing student skills in the use of e-textbooks, the purchasing of additional e-book resources (e.g., computer labs), and the education of students about the benefits of e-book resources are among the strategies that have been proposed to improve e-textbook experience among students (Sun et al., 2012; Zhang \& Beckman, 2011). 
This study seeks to investigate the following: (1) How does students' willingness to try out new information technology - technology innovativeness - affect e-textbook use perceptions? (2) How does technology innovativeness fit into the technology acceptance model framework in determining acceptance of e-textbooks? (3) How is acceptance and use of e-textbook by students affected by students' exposure to the technology as required by instructors in course implementation? This paper utilizes the technology acceptance model, a well-known and accepted framework in predicting user acceptance of technology (Chu \& Chu, 2011; Venkatesh \& Davis, 2000). To address these research questions, this study introduces two additional constructs to the core model of the TAM. First, the relationships between technology innovativeness and the TAM constructs are tested; and the impact of e-textbook exposure and the difference it makes on user acceptance between high-level versus low-level of exposure is also examined.

\section{Literature Review}

There has been a paradigm shift in information technology literature from the $90 \mathrm{~s}-\mathrm{a}$ look at technology from the end-user perspective instead of the manufacturer. This major shift began with Davis's (1986) Technology Acceptance Model (TAM) derived from the Theory of Reasoned Action (TRA) first proposed by Fishbein and Ajzen (1975). Simply put, Davis' model proposes that the behavioral intention to use (BI) a target system is determined by the perceived usefulness (PU), defined as the subjective perception that a technology is useful to an individual in question, and perceived ease of use (EOU), defined as the subjective perception that the technology is easy to use. From these three foundational constructs, an extension was further made based the TRA and the Theory of Planned Behavior (TPB) to include a new construct known as subjective norm (Venkatesh \& Davis, 2000). The subjective norm (SN) depicting social influences was defined as a person's perception that most people who are important to them think they should or should not perform a particular behavior. Though the SN was found not to have a significant effect on intention by some researchers (Davis, Bagozzi, \& Warshaw, 1989; Mathieson, 1991), Taylor and Todd (1995) did. Because of this, the extension of the of the original TAM model to include SN became known as the TAM2.

The TAM model is famous for its use to predict the intention to use varying technologies. Different researchers have looked into different aspects pertaining to varying areas of e-learning and mobile media. E-learning is broadly defined as instruction delivered via all electronic media including the Internet, intranets, extranets, satellite broadcasts, audio/video tape, interactive TV, and CD-ROM (Govindasamy, 2002). For instance, some investigators have focused on the acceptance of the Blackboard System (e.g., Yi \& Hwang, 2003), while some have concentrated on student websites (e.g., Selim, 2002). Yet, others have examined perceptions of e-learning from the educators' perspective across different countries (e.g., Demirbilek, 2010) while others have looked into a combination of the different aspects (Duan, He, Feng, Li, \& Fu, 2010). The acceptance of e-learning has also been studied in different national and cultural settings, e.g., the United States (Yi \& Hwang, 2003), China (Duan et al., 2010), Malaysia (Govindasamy, 2002), and South Korea (Lee, Yoon \& Lee, 2009) among others.

Nevertheless, research shows that actual e-textbook adoption remains a challenge (Sun, Flores, \& Tanguma, 2012). Many researchers have acknowledged the fact that e-textbook usage has been limited to that which enables users to gain snippets of information and fact-finding but not for reading of large amounts of text (Brunet et al., 2011; Nicholas et al., 2010). This problem warrants an investigation into other factors that influence e-textbook acceptance among students and that affect the adoption of the technology. And though personal technology innovativeness (defined as willingness of an individual to try out any new information technology) has already been hypothesized to influence both antecedents and consequences of adoption perceptions (see Agarwal \& Prasad, 1998), only few researchers (e.g., Lu, Yao, \& Yu, 2005) have leveraged its 
usage with the technology acceptance model. Additionally, the role of system exposure (defined as the frequency of use and technology training) has received very little attention and has remained vastly unexplored vis-à-vis its relationship with adoption decisions.

Nevertheless, the increasing adoption and use of e-textbooks in the learning process means that a careful examination of user-acceptance and issues that impact e-textbook learning should be given a closer look. Individual technology innovativeness has both practical and theoretical implications especially for a new technology like the e-textbook. First, identifying technology innovativeness as a key attribute in the process of adoption of new technology is of paramount practical importance. These adopters act as opinion leaders and change agents who can be isolated and studied. Empirically-speaking, knowledge of the impact of individual technology innovativeness in the acceptance and adoption process will widen understanding of the role of individual traits (Agarwal \& Prasad, 1998). On the other hand, exposure to information systems (i.e., frequency of use and technology training) has been found to influence work engagement (i.e., vigor, dedication, and absorption) to the extent it is mediated by positive appraisal (Salanova \& Llorens, 2009). These results suggest that positive appraisal due to appropriate exposure to an information system is likely to produce positive results in personal acceptance and, hence, adoption. Given that system exposure will affect individual perceptions, this study proposes system exposure as a moderator of technology acceptance relationships.

Clearly, very little research has leveraged technology innovativeness with acceptance or adoption of technology decisions. The role of system exposure, on the other hand, is seldom used to understand the adoption process. In this study, we not only look at e-textbook acceptance in a university environment, but also examine the relationship between technology innovativeness on etextbook acceptance. Additionally, the impact of e-textbook system exposure on the TAM constructs is also assessed. By the term "system" is meant all the interconnection of hardware, software, and content that constitute a given technology.

\section{Research Model and Hypotheses}

The research model and hypotheses are summarized in Figure 1. The model comprises the five constructs, namely, technology innovativeness (TI), subjective norm (SN), perceived usefulness $(\mathrm{PU})$, perceived ease of use (EOU) and behavioral intention to use (BI). The model further proposes that the exposure to e-textbook learning system will moderate the relationships: SN-PU, SN-BI, TI-PU, TI-BI, PU-BI, EOU-PU and EOU-BI.

\section{Personal Technology Innovativeness}

Rogers (1983) defines diffusion as the process by which an innovation is communicated through certain channels over time among the members of a social system. In his work, Rogers further proposes four elements that must be present in the diffusion of innovation process, namely, innovation, communication channels, time, and social system. The innovation component has been hypothesized further to comprise competitive advantage, complexity, observability, and triability (Rogers, 1983).

However, it was not until 1998 when Agarwal and Prasad (1998) proposed personal innovativeness in the domain of information technology as a new construct, developed from previous works including Rogers's. Personal innovativeness in information technology, otherwise referred to in this paper as technology innovativeness (TI), is defined as the "willingness of an individual to try out any new information technology" (Agarwal \& Prasad, 1998). It is defined and understood as a trait and is conceptualized to be invariant across situational considerations. Hence, TI is understood to be a stable and reliable construct. Because it is a "personal" trait, it can essentially be classified as intrinsic in nature. This distinction is important because TI is hypothesized to be as- 


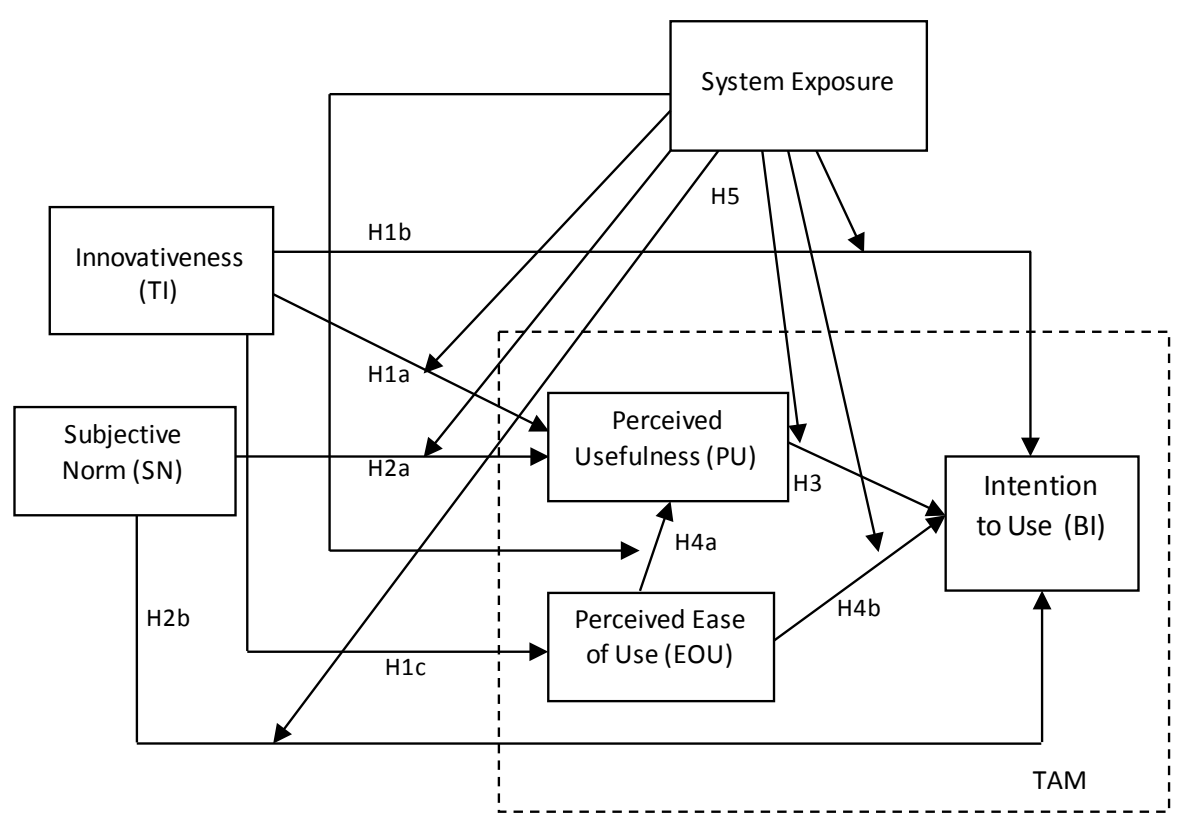

Figure 1: Research model and hypothesis

sociated with perceived usefulness, which itself is a precursor of behavioral intention to use a technology. It can be said, therefore, that TI can intrinsically influence the way people perceive the usefulness of a particular technology in question. In other words, the willingness to try out new technology is likely to influence the way an individual perceives the usefulness of a new technology. In addition, willingness to try out new technologies (TI) would also influence the intention to use the technology. TI can achieve this by directly influencing intention to use (as proposed in the model in Figure 1) or indirectly through perceived usefulness.

In this paper technological innovativeness refers to the belief that an individual is "open" to try out e-book technology. It is operationalized as proposed by previous research (Agarwal \& Prasad, 1998). It is hypothesized that technology innovativeness or the openness of an individual to new technology will influence perceived usefulness (the belief that it will help individuals accomplish their desired outcomes) and the behavioral intention to use new technology - in this case, e-book technology. It has been determined from previous research that the intention to carry out a particular behavior can be predicted by the attitude towards a particular behavior in question (Ajzen, 1991).

Since intention is determined by an attitude towards a particular behavior, it could be said, therefore, that the attitude of "openness" to technology is likely to influence the intention to use a particular technology in question. This is reasonably so, because openness to try out any technology, in general, will lead to willingness to try out specific technology in particular. Hence, it is hypothesized:

H1a. Personal technology innovativeness will positively affect perceived usefulness of the etextbook learning.

H1b. Personal technology innovativeness will positively affect the behavioral intention to use e-textbook learning.

H1c. Personal technology innovativeness will positively affect perceived ease of use of etextbook learning. 


\section{Subjective Norm}

The "perceived social pressure to perform or not perform a behavior" (Ajzen, 1991, p. 188) is called the subjective norm. In business organizations, though the use of technology might be considered voluntary, the reward systems and the desire for promotion can cause employees to want to comply with their supervisors (Taylor \& Todd, 1995). Here, influence is accepted to gain a favorable response from a person or group (Venkatesh \& Davis, 2000). In an academic milieu, the desire for students to use a system through influence from teachers or peers in order to succeed is very possible. Subjective norms have been hypothesized to have an impact on perceived usefulness and behavioral intention to use (Venkatesh \& Davis, 2000). Thus:

H2a. Subjective norms will positively affect perceived usefulness of e-textbook learning.

$\mathrm{H} 2 \mathrm{~b}$. Subjective norms will positively affect the behavioral intention to use e-textbook learning technology.

\section{Perceived Usefulness, Perceived Ease of Use, and Intention to Use}

In the e-textbook learning context, perceived usefulness refers to the belief by an individual that the e-textbook is useful in order to enhance their performance (c.f., Davis, 1989). It has also long been established in literature that there exists a relationship between perceived usefulness and the behavioral intention to use a system (Davis, 1989; Venkatesh \& Davis, 2000; Venkatesh \& Morris, 2000). Perceived ease of use, defined in literature as the belief that a use of a particular technology is free of effort (Davis, 1989), points to the end that perceived ease of use will both affect perceived usefulness and the behavioral intention to use a system (Davis, 1989; Venkatesh \& Davis, 2000; Venkatesh \& Morris, 2000). The use of a system has been long hypothesized to be dependent on behavioral intention to use (Davis, 1989). Since intention is predicted by attitude towards an act (Ajzen, 1991), it is reasonable to predict that favorable attitudes will lead to a favorable behavior. Therefore, we propose:

H3. Perceived usefulness will positively affect the behavioral intention to use e-textbook learning technology.

H4a. Perceived ease of use will positively affect the perceived usefulness of e-textbook learning technology.

H4b. Perceived ease of use will positively affect the behavioral intention to use e-textbook learning technology.

\section{Exposure to Information Technology}

Exposure to information technology, otherwise referred to in this paper simply as system exposure, is defined as "the frequency of use and technology training" (Chua \& Chen, 1999) that an individual has. While it is true that literature also reveals other indicators besides these, e.g., the amount of time using technology, times used before feeling comfortable, frequency of technology training, use of technology at work and at home, personal computer ownership, computer usage frequency and level (Salanova \& Llorens, 2009), the most used indicators are the two chosen in this study - the frequency of use and technology training. Since training and frequency of use are skills that can be acquired, and that come from outside of the individual, these are considered extrinsic factors that can affect an individual's acceptance or "rejection" of technology. This extrinsic element is contrasted with technology innovativeness which is a more individual trait and comes from a person's disposition.

Previous researchers have hypothesized system exposure to have a positive relationship with the appraisal of technology (Salanova \& Schaufeli, 2000). Since appraisal of technology is influenced 
by system exposure, it can be expected that the extent to which an individual is exposed to the system will affect their perception towards acceptance of the system. Hence, it is proposed:

H5. Exposure to the e-textbook system will moderate all user-perception relationships in the model.

According to the proposed model, therefore, it can be noted that while intrinsic factors like technology innovativeness associate and influence the TAM relationships, extrinsic factors like system exposure rather play the role of moderating them. In this study, two levels of system exposure are explored as described in the methodology section: high exposure (full implementation) and low exposure (partial implementation).

\section{Methodology}

This study seeks to investigate the following: (1) How students' willingness to try out new information technology - technology innovativeness - affects e-textbook use perceptions. (2) How does technology innovativeness fit into the technology acceptance model framework in determining acceptance of e-textbooks? (3) How is acceptance and use of e-textbook by students affected by their exposure to the technology as required by instructors in course implementation? This paper utilizes the technology acceptance model (TAM) to predict user acceptance as proposed by Venkatesh and Davis (2000). To address the three research questions this study introduces two additional constructs to the core model of TAM. First, the relationships between technology innovativeness and the TAM constructs are tested. For investigating the impact of e-textbook exposure, the difference it makes on user acceptance between high-level versus low-level of exposure is uncovered.

\section{Subjects}

The target population of this study comprises college students who take the courses that adopt etextbooks. The sample was drawn from a southwest university where a sponsored project encouraged instructors to use e-textbook in class. From the cluster of courses that adopted the technology, 158 undergraduate students comprised of 70-male and 88-female were selected. The students were from different majors and each student had an experience with using computers for educational purposes for at least 3 years. Student subjects using cluster sampling is appropriate for this study, as the participants must have some exposure to e-textbook in the courses that they take.

The number of survey questionnaires collected totaled 158 from a distributed total of 167 questionnaires, for five sections of an upper-level undergraduate business statistics course. The response rate from the 13 -item questionnaire was $94.6 \%$. The original survey was pretested with some undergraduate students to check for clarity of items and feedback. The student participants in the study were asked to check the response that best described their level of agreeableness to each item on the survey. The overall male-to-female ratio was 1:1.3.

Three sections of this course, totaling 77 students, were undergoing a complete e-textbook learning implementation program. Full implementation of this program meant that the students' learning, assignments, examinations, and feedback were completely supported online, i.e., paperless. These are tagged in this study as "high" on system exposure. For the remaining 81 students drawn from an additional three sections of the course, e-textbook learning implementation was partial: students studied online but carried out assignments and testing in a pen-and-paper fashion, analogous to a regular traditional learning style. This study tagged this latter group as "low" on system exposure. The ratio of full-to-partial implementation was 1:1.1. These two groups therefore differed in the level of technology exposure to the e-book. 


\section{Measures}

The survey items were implemented through a five-point Likert scale measure. The scales used were adopted from validated scales of the previous studies of (Agarwal \& Prasad, 1998; Davis 1989; Taylor \& Todd, 1995; Venkatesh \& Davis, 2000). Each of these scales was then adapted to fit the e-textbook context of study. Consistent with social research, demographic variables were also collected especially gender. The fully itemized questionnaire is provided in the Appendix.

\section{Data Analysis}

Collected data was then coded and analyzed for missing data values. Confirmatory factor analysis (CFA) and structural equation modeling (SEM) technique were conducted using AMOS statistical software. Following the recommended two-step approach (Hair, Black, Babin, Anderson, \& Tatham, 2009), this study used CFA to assess the measurement validity and then used SEM to test the research model. Both CFA and SEM have been used extensively in information systems related research (Chin \& Todd, 1995; Compeau \& Higgins, 1995; Venkatesh \& Morris, 2000) to examine the relationship between constructs and the strength of such relationships.

The specific statistical techniques used depend on the nature of variables. In the research model there are two exogenous variables, technology innovativeness and subjective norm. Without other antecedents, they exert influences on endogenous variables, including perceived usefulness, perceived ease-of-use, and behavioral intention. In the terminology of regression analysis, the exogenous variables correspond to independent variables, and endogenous variables correspond to dependent variables. Regression analysis can only deal with one dependent variable at a time, but structural equation modeling can handle multiple endogenous variables. This makes it possible to test a mediating relationship that involves at least one exogenous variable and two endogenous variables. For instance, technology innovativeness first influences perceived usefulness and perceived ease-of-use, which then affect behavioral intention.

In comparison to other continuous variables in the model, e-textbook exposure is a categorical variable that has two levels, high versus low. Instead of the linear relationships, it is hypothesized to have moderating effects on the relationships among other variables. In regression analysis, a moderating effect is typically tested with the interaction term between an independent variable and a moderating variable. But in structural equation modeling it is more straightforward to use multi-group analysis to compare the existing relationships in a model across two split samples using the moderator e-textbook exposure as the grouping variable.

For the validation of the measures used in this study, the measurement model shown in Figure 3 was estimated. The model includes all the constructs in the research model and their indicators. The figure includes the estimated factor loadings and factor correlations. The assessment of the measurement model before testing the structural model meets the requirement of two-step approach as recommended for behavioral research that must take measurement errors into account (Hair et al., 2009). 


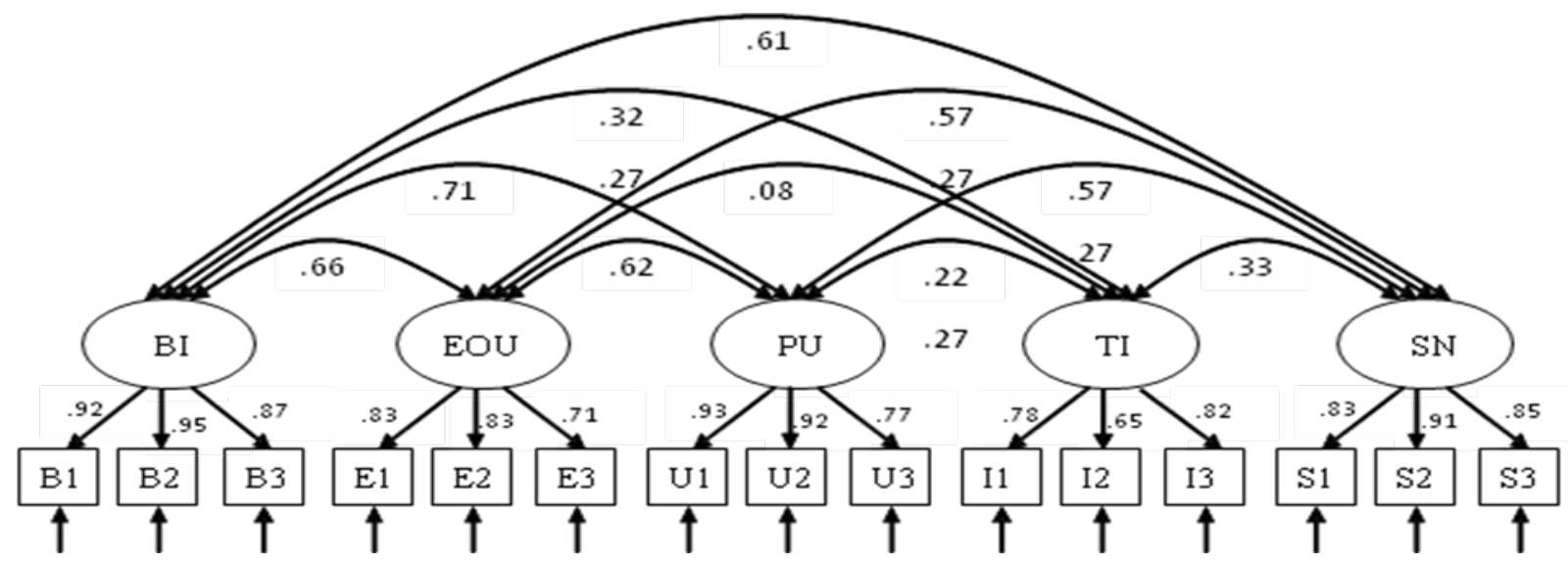

Figure 3: Confirmatory factor analysis results

The goodness-of-fit indices are reported in Table 1. The model fit was generally adequate for both the full-sample analysis and split-sample multigroup analysis. The result confirmed that the measurement model provided a good representation of the factorial structure of observations. According to the two-step approach, if a measurement model contains all the constructs in the structural model to be tested later, the adequate model fit of the former assure the accuracy of the estimation of the structural relationships (Hair et al., 2009).

\begin{tabular}{|l|c|c|c|c|}
\hline \multicolumn{1}{|c|}{ Table 1: Goodness-of-fit of Measurement Models } \\
\hline \multicolumn{1}{|c|}{ Goodness-of-fit measure } & Recommended value & Full-sample & Split-sample & Comment \\
\hline Chi-square/df & $<=3.00$ & 2.067 & 1.946 & Adequate \\
\hline Non-Normed Fit Index (NNFI) & $>=0.9$ & 0.930 & 0.889 & Adequate \\
\hline Comparative Fit Index (CFI) & $>=0.9$ & 0.946 & 0.915 & Adequate \\
\hline Root mean square (RMSEA) & $<=0.08$ & 0.082 & 0.078 & Adequate \\
\hline
\end{tabular}

Table 2 summarizes some descriptive statistics including the means, standard deviations, the reliability measures, and variance extracted (VE) for each of the constructs. The value for each descriptive is given for the general, partial, and full implementation samples. Results showed that the mean responses did not differ much across the two programs. Perceived usefulness (PU) had the highest mean values but perceived ease of use (EOU) had the lowest mean values for both full and partial implementation programs. Participants generally agreed that e-textbooks were helpful for their learning but they are concerned about the usability of the technology.

All constructs met the threshold for reliability with a Cronbach's alphas exceeding the 0.7 level as recommended by Nunnally (1978). Factor loadings of all the constructs were greater than the 0.5 threshold level and the variances extracted were also all greater than the 0.5 recommended levels; hence, convergent validity was ascertained (Hair et al., 2009). Discriminant validity was also de- 
termined to be adequate. Specifically, the variance extracted for each construct was greater than all the squared inter-factor correlations associated with the factor in question (Hair et al., 2009).

\begin{tabular}{|c|c|c|c|c|c|c|}
\hline \multicolumn{7}{|c|}{ Table 2: Descriptive statistics } \\
\hline \multirow[b]{2}{*}{ Construct } & \multirow[b]{2}{*}{ Cronbach's $\alpha$} & \multirow[b]{2}{*}{$\mathbf{V E}$} & \multicolumn{2}{|c|}{$\begin{array}{c}\text { Full implementation } \\
(\mathrm{n}=77)\end{array}$} & \multicolumn{2}{|c|}{$\begin{array}{c}\text { Partial implementation } \\
(\mathrm{n}=81)\end{array}$} \\
\hline & & & Mean & SD & Mean & SD \\
\hline TI & .79 & 0.57 & 3.49 & 0.80 & 3.58 & 0.71 \\
\hline SN & .90 & 0.75 & 3.97 & 0.87 & 3.85 & 0.73 \\
\hline $\mathbf{P U}$ & .90 & 0.77 & 4.16 & 0.81 & 4.16 & 0.62 \\
\hline EOU & .83 & 0.63 & 3.45 & 0.59 & 3.37 & 0.65 \\
\hline BI & .93 & 0.84 & 3.86 & 0.98 & 3.83 & 0.87 \\
\hline
\end{tabular}

\section{Findings and Discussion}

The complete results of the analyses are presented in Table 3. It displays the results of the hypothesis-testing for the overall, full, and partial samples side-by-side to allow the comparison between the implementation programs. The estimates of the structural relationships in the research model are also specified along with their corresponding levels of significance.

\begin{tabular}{|l|c|c|c|c|}
\hline \multicolumn{5}{|c|}{ Table 3: Complete Test Results } \\
\hline Hypothesis & Path & Overall & Full & Partial \\
\hline H1a & PU<---TI & $.038(.088)$ & $.194(.115)^{*}$ & $.079(.127)$ \\
\hline H1b & BI<---TI & $.201(.100)^{*}$ & $.277(.120)^{* *}$ & $.058(.156)$ \\
\hline H1c & EOU<---TI & $.101(.098)$ & $-.012(.106)$ & $.341(.169)^{*}$ \\
\hline H2a & PU<---SN & $.315(.071)^{* *}$ & $.307(.084)^{* *}$ & $.185(.102)^{*}$ \\
\hline H2b & BI<---SN & $.197(.080)^{* *}$ & $.129(.096)$ & $.261(.129)^{*}$ \\
\hline H3 & BI<---PU & $.516(.104)^{* *}$ & $.640(.156)^{* *}$ & $.496(.164)^{* *}$ \\
\hline H4a & PU<---EOU & $.455(.082)^{* *}$ & $.882(.161)^{* *}$ & $.249(.081)^{* *}$ \\
\hline H4b & BI<---EOU & $.409(.099)^{* *}$ & $.229(.203)$ & $.405(.111)^{* *}$ \\
\hline
\end{tabular}

Note: Standard errors of the estimates are given in parentheses; ${ }^{*}$ - significant at the 0.05 level; ${ }^{*}$ - significant at the 0.01 level; one-tail test because all relationship hypothesized are positive linear. PU- Perceived Usefulness; TI-Technology Innovativeness; BI-Behavioral Intention; EOU-Perceived Ease of Use; SNSubjective Norm 


\section{Technology Innovativeness Relationships}

The results showed that technology innovativeness (TI) had a significantly positive effect on perceived usefulness (PU) and behavioral intention (BI) in the case of full implementation of etextbook meanwhile. However, the relationship between technology innovativeness and perceived ease of use (EOU) was only significant in the partial implementation subsample.

These results seem to suggest that students' willingness to try out new information technologies is a very important determinant of use decisions in full implementation (greater system exposure) environments. In other words, as long as students have the choice to only partially use etextbooks, personal technology innovativeness did not exert a significant influence on use decisions. Hence, in full use technology environments, TI is likely to be a very important determinant of intention to use.

Interestingly, only in partial implementation environments, did we see the willingness to try new technology to impact ease of use. This result suggests that the decision to use a system based on its ease of use is determined by the individual's willingness to try out new technologies only if the user did not need to fully use the system.

\section{Subjective Norm Relationships}

The relationship between subjective norm $(\mathrm{SN})$ and perceived usefulness $(\mathrm{PU})$ was stronger in full implementation than in the partial implementation subsample. However, in the relationship between subjective norm and behavioral intention, only the partial implementation subsample scored a significant result.

These results seem to suggest that the influence of significant others (subjective norm) in determining behavioral intentions to use e-textbooks are more important in partial use environments than in full implementation environments. This means that normative influences are likely to more important only when there is a limited exposure to a given technology than in greater exposure environments.

\section{Perceived Ease of Use Relationships}

Generally, all perceived ease of use (EOU) relationships were significant (not surprising) with the exception of its relation with technology innovativeness (TI) which has been discussed above. This simply means that the more e-textbooks are perceived as easy to use, the greater the likelihood of being accepted and used. This is not surprising given that many TAM studies come out with the same conclusion (see Davis, 1989; Venkatesh \& Davis, 2000). However, the results also show that in partial implementation environments, ease of use was important in the determination of behavioral intention to use e-textbooks, but not so in full implementation environments. This also means that perceived ease of use of a particular technology may be immaterial in determining use intentions in full implementation settings. In other words, in full implementation settings individuals are likely to be less driven by ease of use in their decision to use a particular technology and more by the perceived usefulness.

\section{Perceived Usefulness Relationships}

Generally, all perceived usefulness (PU) relationships were significant with the exception of that with technology innovativeness (TI). We could conclude that PU impacts use intentions at all levels irrespective of type of implementation. Similarly, the results point to the end that PU is the strongest determinant of use intentions. This result is consistent with other TAM studies like Davis (1989) and Venkatesh and Davis (2000). 


\section{Moderation Effects of System Exposure}

The results of the hypothesis testing are summarized in Table 4. In general, in the full implementation subsample versus the partial implementation subsample, three hypotheses were not supported. Specifically, these relationships were TI-EOU, SN-BI, and EOU-BI. Overall, when the two subsamples were tested for the moderating effects of full implementation (or high exposure to technology) versus partial implementation (low exposure to technology), a significant difference was found. This result indicates that the type of implementation program used was a significantly strong moderator for e-textbook adoption behavior. That is, most of the relationships in the model were significantly different across the two types of implementation, i.e., full versus partial.

In particular, five out of the eight hypothesized relationships (H1a, H1b, H1c, H2b, and H4b) varied significantly between full and partial implementation groups. System exposure moderated the effects on behavioral intention by the two predictive variables: perceived ease-of-use and subjective norm.

The moderating effects of system exposure were found to be more salient on the relationships involving technology innovativeness. In the full implementation group, technology innovation had significant effects on perceived usefulness and behavioral intention, but not on perceived ease of use. In the partial implementation group, however, the relationships exhibited opposite patterns: the only one that is significant is between technology innovativeness and perceived ease-ofuse.

\begin{tabular}{|l|l|l|l|l|}
\hline \multicolumn{5}{|c|}{ Table 4: Summary of Test Results } \\
\hline Hypothesis & \multicolumn{1}{|c|}{ Relationship } & \multicolumn{1}{|c|}{ Overall } & \multicolumn{1}{c|}{$\begin{array}{c}\text { Full } \\
\text { implementation }\end{array}$} & $\begin{array}{c}\text { Partial } \\
\text { implementation }\end{array}$ \\
\hline H1a & Technology Innovativeness $\rightarrow$ Perceived Usefulness & Not supported & Supported & Not supported \\
\hline H1b & $\begin{array}{l}\text { Technology Innovativeness } \rightarrow \text { Behavioral Intention } \\
\text { to Use }\end{array}$ & Supported & Supported & Not supported \\
\hline H1c & Technology Innovativeness $\rightarrow$ Perceived Ease of Use & Not supported & Not Supported & Supported \\
\hline H2a & Subjective Norm $\rightarrow$ Perceived Usefulness & Supported & Supported & Supported \\
\hline H2b & Subjective Norm $\rightarrow$ Behavioral Intention to Use & Supported & Not supported & Supported \\
\hline H3 & Perceived Usefulness $\rightarrow$ Behavioral Intention to Use & Supported & Supported & Supported \\
\hline H4a & Perceived Ease of Use $\rightarrow$ Perceived Usefulness & Supported & Supported & Supported \\
\hline H4b & Perceived Ease of Use $\rightarrow$ Behavioral Intention to Use & Supported & Not supported & Supported \\
\hline
\end{tabular}

\section{Limitations and Implications of Study}

This research had some limitations. First, the choice of undergraduate students for the sample means that the results should be interpreted with caution. Additionally, because these students had an initial exposure to online learning environment, their perceptions could have been influenced by the experience. This could especially affect perceptions of the ease of use of the etextbook. Consequently, the context of the study necessitates that all results be interpreted accordingly. Nevertheless, since undergraduate students represent the bulk of all e-book users (see 
Hernon et al., 2007), the study's representativeness is still valid. Future research could investigate the impacts of $T I$ and system exposure in varying educational levels and across settings.

Despite the limitations, the findings have several theoretical and practical implications. This study contributes to theory in that it increases our understanding of the impact of use decisions as influenced by a dispositional trait such as technology innovativeness, while highlighting the moderating effect of a more extrinsic factor such as system exposure or type of implementation. By using the technology acceptance model (TAM), we also ascertained the strength and stability of the core model in predicting acceptance and usage decision. Additionally, consistent with previous research using the TAM we show that the antecedents of the core model are responsible for determining use or usage decisions.

The findings also provide practical insights for teachers. First, students' openness to new technology in general will likely positively affect the adoption of a specific instructional technology like e-textbooks. The effect of technology innovativeness - being an intrinsic trait - suggests that dispositional and trait-based factors are likely to affect the decision for students to "accept" or "reject" instructional technology. Additionally, the results seem to suggest that personal technology innovativeness would be critical in determining behavioral intention to use a new instructional technology in mandatory-use settings. This is particularly true when we consider the result the relationship between TI and BI in the case of full implementation. Here, results suggested that TI strongly influenced behavioral intention.

Teachers and educators will have to focus on helping students become readily willing to take on new technologies first, before the implementation of new systems. It might be helpful to conduct trainings and information sessions that will help students deal with anxieties about the use of new technologies, providing resourceful persons within the institution to whom students can turn to in the face of difficulties. Such facilitating conditions may be helpful in boosting technology innovativeness.

Second, the findings imply that pedagogues and instructional methodologists must leverage both the advantage of new learning technologies to the reality of student perceptions and use. An intrinsic factor such as students' technology innovativeness should therefore be factored into instructional technology usage decision-making models. Additionally, an extrinsic but related factor such as exposure to the technology should equally be considered as it is likely to moderate students' acceptance. Going forward, instructional technology leaders must reflect on the full package of e-textbook delivery. The greater the ease of use, versatility, media richness, and even compatibility with students' learning habits, the better the electronic experience. Greater electronic experiences will lead to greater exposure which will boost acceptance and adoption by students.

Lastly, the publishers of e-textbook would find these results helpful. It broadens understanding as to what factors contribute to e-textbook acceptance among collegians, who are arguably the greatest and most important users of e-book learning (Hernon et al. 2007. As it stands, student's willingness to try new technology (technology innovativeness) is important in determining the acceptance and use of e-textbooks among college students. Since technology innovativeness did not lead to use intentions in partial implementation environments, this suggests that e-textbook publishers may need to run free trial versions of these products to build some level of experience and inspire future desire to use a similar technology. Additionally, more intuitive designs can be employed. The inclusion of tools that will lead to deeper and richer experiences in the electronic environment would be helpful in improving student acceptance and adoption through greater system exposure. 


\section{Conclusion}

This study examined the role of technology innovativeness (people's openness to new technology) in determining students' acceptance of e-textbooks. The findings suggest that students' willingness to try new technology has both a direct positive impact as well as an indirect influence on their intention to use e-textbooks. The study further showed how technology innovativeness can be incorporated into the technology acceptance model to study how the adoption of new technology happens. Additionally, the study shows how the amount of exposure to a given technology can moderate acceptance, adoption, and use behaviors of a given technology.

It is suggested that educators be involved in boosting students' personal innovativeness prior to new systems implementation. This could be achieved by offering new informational and training course modules that focus on motivating students towards tactical and strategic use of educational technologies with emphasis on what these students stand to gain from using these new technologies. Additionally, since the amount of exposure to a given technology seemed to significantly moderate technology adoption relationships, system developers must tweak the technology for maximum navigational and educational experience. To achieve these two objectives, the following are suggested: education and skill-building targeting the use of electronic resources and systems (Zhang \& Bekman, 2011); increase in number and diversity of electronic resources (e.g., computer labs) on campuses (Sun et al., 2012); improvement of e-textbook system experience through media richness (Lai \& Chang, 2011; and the provision of institutional support or facilitating conditions (e.g., instructor assistance) for easier e-textbook adoption (Ifenthaler \& Schweinbenz, 2013).

\section{References}

Agarwal, R., \& Prasad, J. (1998). A conceptual and operational definition of personal innovativeness in the domain of informational technology. Information Systems Research, 9(2), 204-215.

Ajzen I. (1991). The theory of planned behavior. Organizational Behavior and Human Decision Processes, $50(2), 179-211$.

Brunet, D. P., Bates, M. L., Gallo, J. R., \& Strother, E. A. (2011). Incoming dental students' expectations and acceptance of an electronic textbook program. Journal of Dental Education, 75(5), 646-652.

Chin, W. W., \& Todd, P. A. (1995). On the use, usefulness, and ease of use of structural equation modeling in MIS research: A note of caution. MIS Quarterly, 19(2), 237-246.

Chu, A. Z. C., \& Chu, R. J. C. (2011). The intranet's role in newcomer socialization in the hotel industry in Taiwan-technology acceptance model analysis. The International Journal of Human Resource Management, 22(05), 1163-1179.

Chua, S. L., \& Chen, D. T. (1999). Computer anxiety and its correlates: A meta-analysis. Computer Human Behavior, 15, 609-623.

Compeau, D. R., \& Higgins, C. A. (1995). Computer self-efficacy: Development of a measure and initial test. MIS Quarterly, 19(2), 189-211.

Davis, F. D. (1986). A technology acceptance model for empirically testing new end-user information systems: Theory and results. (Doctoral dissertation). Sloan School of Management, Massachusetts Institute of Technology.

Davis, F. D. (1989). Perceived usefulness, perceived ease of use, and user acceptance of information technology. MIS Quarterly, 13(3), 318-339.

Davis, F. D., Bagozzi, R. P., \& Warshaw, P. R. (1989). User acceptance of computer technology: A comparison of two theoretical models. Management Science, 35(8), 982-1003. 
Demirbilek, M. (2010). Investigating attitudes of adult educators towards educational mobile media and games in eight European countries. Journal of Information Technology Education: Research, 9, 235247. Retrieved from http://www.jite.org/documents/Vol9/JITEv9p235-247Demirbilek777.pdf

Duan, Y., He, Q., Feng, W., Li, D., \& Fu, Z. (2010). A study on e-learning take-up intention from an innovation adoption perspective: A case in China. Computers \& Education, 55(1), 237-246.

Fishbein, M., \& Ajzen, I. (1975). Belief, attitude, intention, and behavior: An introduction to theory and research. Reading, MA: Addison-Wesley.

Govindasamy, T. (2002). Successful implementation of e-learning pedagogical considerations. Internet and Higher Education, 4, 287-299.

Hair, J. F., Black, B., Babin, B., Anderson, R. \& Tatham, R.L. (2009). Multivariate data analysis (7th ed.). Englewood Cliffs, NJ: Prentice Hall.

Hernon, P., Hopper, R., Leach, M. R., Saunders, L. L., \& Zhang, J. (2007). E-book use by students: Undergraduates in economics, literature, and nursing. The Journal of Academic Librarianship, 33(1), 3-13.

Ifenthaler, D., \& Schweinbenz, V. (2013). The acceptance of Tablet-PCs in classroom instruction: The teachers' perspectives. Computers in Human Behavior, 29(3), 525-534.

Ismail, R., \& Zainab, A. N. (2005). The pattern of e-book use amongst undergraduates in Malaysia: A case of to know is to use. Malaysian Journal of Library and Information Science, 10(2), 1-23.

Lai, J. Y., \& Chang, C. Y. (2011). User attitudes toward dedicated e-book readers for reading: The effects of convenience, compatibility and media richness. Online Information Review, 35(4), 558-580.

Lamothe, A. R. (2013). Factors influencing the usage of an electronic book collection: Size of the e-book collection, the student population, and the faculty population. College \& Research Libraries, 74(1), 3959 .

Lee, B-C., Yoon, J-O., \& Lee, I. (2009). Learners' acceptance of e-learning in South Korea: Theories and results. Computers \& Education, 53, 1320-1329.

Lu, J., Yao, J. E., \& Yu, C. S. (2005). Personal innovativeness, social influences and adoption of wireless Internet services via mobile technology. The Journal of Strategic Information Systems, 14(3), 245-268.

Mathieson, K. (1991). Predicting user intentions: Comparing the technology acceptance model with the theory of planned behavior. Information Systems Research, 2(3), 173-191.

Maynard, S., \& Cheyne, E. (2005). Can electronic textbooks help children to learn? The Electronic Library, 23(1), $72-81$.

Nicholas, D., Rowlands, I., \& Jamali, H. R. (2010). E-textbook use, information seeking behaviour and its impact: Case study business and management. Journal of Information Science, 36(2), 263-280.

Nunnally, J. C. (1978). Psychometric theory (2nd ed.). New York: McGraw-Hill.

Reynolds, R. (2011). Trends influencing the growth of digital textbooks in US higher education. Publishing Research Quarterly, 27(2).

Rogers, E. M. (1983). Diffusion of innovations (3rd ed.). New York: The Free Press.

Salanova, M., \& Llorens, S. (2009). Exposición a la tecnología de la información y la comunicación y su relación con el engagement [Exposure to information and communication technology and its relationship to work engagement). Ciencia y Trabajo, 11(32), 55-62.

Salanova, M., \& Schaufeli, W. B. (2000). Exposure to information technology and its relation to burnout. Behaviour \& Information Technology, 19(5), 385-392.

Selim, H. M. (2002). An empirical investigation of student acceptance of course websites. Computers \& Education, 40, 343-360.

Sun, J., Flores, J., \& Tanguma, J. (2012). E-textbooks and students' learning experiences. Decision Sciences Journal of Innovative Education, 10(1), 63-77. 
Taylor, S., \& Todd, P. A. (1995). Understanding information technology usage: A test of competing models. Information Systems Research, 6, 144-176.

Venkatesh, V., \& Davis, F. D. (2000). A theoretical extension of the Technology Acceptance Model: Four longitudinal field studies. Management Science. 46(2), 186-204.

Venkatesh, V., \& Morris, M. G. (2000). Why don't men ever stop to ask for directions? Gender, social influence, and their role in technology acceptance and usage behavior. MIS Quarterly, 24(1), 115-139.

Wilson, R., \& Landoni, M. (2001). Evaluating electronic textbooks: A methodology. In P. Constantopoulos and I.T. Sølvberg (Eds.), Research and advanced technology for digital libraries (pp. 1-12). Springer Berlin Heidelberg.

Yi, M. Y., \& Hwang, Y. (2003). Predicting the use of web-based information systems: Self-efficacy, enjoyment, learning goal orientation, and the technology acceptance model. International Journal of Human-Computer Studies, 59, 431-449.

Zhang, Y., \& Beckman, R. (2011). E-book usage among chemists, biochemists and biologists: Findings of a survey and interviews. Issues in Science and Technology Librarianship, 65, 2.

\section{Appendix: Questionnaire Items}

\section{Technological Innovativeness}

TI1 If I heard about a new information technology, I would look for ways to try it out.

TI2 Among my peers, I am usually the first to try out new information technologies.

TI3 I like to experiment with new information technologies.

\section{Subjective Norms}

SN1 People important to me support my use of the e-textbook.

SN2 People who influence me think that I should use the e-textbook.

SN3 People whose opinions I value prefer that I should use the e-textbook.

\section{Perceived Usefulness}

PU1 Using the e-textbook can improve my learning performance.

PU2 Using the e-textbook can increase my learning effectiveness.

PU3 I find the e-textbook to be useful to me.

\section{Perceived Ease of Use}

EOU1 Learning to use the e-textbook is easy for me.

EOU2 It is easy for me to become skillful at using the e-textbook.

EOU3 Overall, the e-textbook is easy to use.

\section{Behavioral Intention to Use}

BI1 I will use e-textbooks for other classes.

BI2 I will continue using e-textbooks in the future.

BI3 I will strongly recommend that others use e-textbooks. 


\section{Biographies}

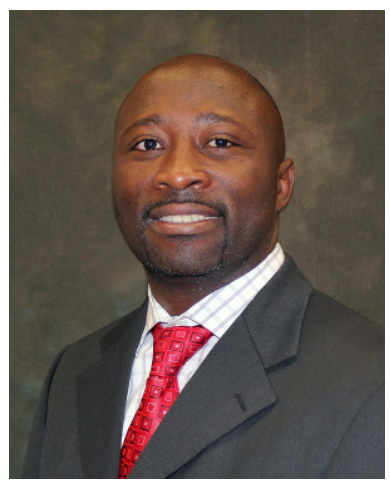

Dr. Madison N. Ngafeeson is an assistant professor of computer information systems at the Walker Cisler College of Business, Northern Michigan University in Marquette, Michigan. His general research interest is in the area of the adoption, implementation, diffusion and use of information systems in organizations; with a special focus in health information systems management. His works have been published in such outlets as the International Journal of Electronic Healthcare, the International Journal of Electronic Government Research, International Journal of Electronic Finance and the proceedings of the European Conference on Information Systems and the Decision Sciences Institute.

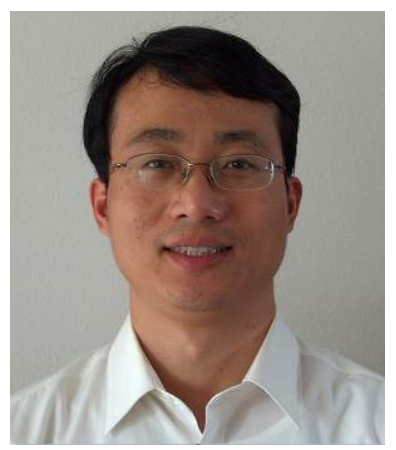

Dr. Jun Sun is an Associate Professor of Information Systems at The University of Texas - Rio Grande Valley. He received his Ph.D. in Information and Operations Management from Texas A\&M University. One of his research interests is the use of information technology for innovative education. Relevant work has appeared in the Decision Sciences Journal of Innovative Education, Information Systems Education Journal, International Journal of Services and Standards, Learning and Individual Differences, and so on. 